DOI: 10.24833 / 0869-0049-2019-3-14-21

\title{
Татьяна Васильевна НОВИКОВА
}

Северо-Кавказский филиал, Российский государственный университет правосудия

им. Леваневского ул., д. 187/1, Краснодар, 350002, Российская Федерация

tnovikova@inbox.ru

ORCID: 0000-0002-8889-0444

Поступила в редакцию: 01.05.2019

Принята к публикации: 05.08.2019

\section{О ЗАКРЕПЛЕНИИ ПРИНЦИПА АВТОНОМИИ ВОЛИ В КОДЕКСЕ БУСТАМАНТЕ}

ВВЕДЕНИЕ. Принцип автономии воли сторон, в первую очередь договорных правоотночениц, является прочно установленным в современном международном частном праве. На протяжении ХХ в. он получал всестороннее развитие в международных договорах, унифииирующих нормы коллизионного права, и в национальном законодательстве многих государств мира. В юридической литературе распространена точка зрения, согласно которой уже первая всеобъемлющая кодификаиия международного частного права Кодекс Бустаманте - провозглашает приниип автономии воли сторон частноправовых отношений международного характера.

МАТЕРИАЛЫ И МЕТОДЫ. Принципиальную установку исследования составляет опора не только на нормативный материал Кодекса Бустаманте, но и на обстоятельства и последствия его разработки, а также на спецификуего применения в государствах-участниках (особенно с учетом сделанных рядом стран оговорок общего характера).

РЕЗУЛЬТАТЫ ИССЛЕДОВАНИЯ. УКаЗб८вается, что Кодекс Бустаманте как всеобъемлющая кодификация международного частного права построен на компромиссных решениях и ратифицирован со множеством оговорок, в том числе сводящих на нет саму идею унификации. Последовательно доказывается, что ст. 3 Кодекса Бустаманте, устанавливающая три категории правовых норм (в том числе доброволь- ных, «применяемых только по избявлению, толкованию или презумпиии воли сторон или одной из сторон»), имеет слишком общий характер, а отрывочные упоминания об автономии воли в аспекте толкования договоров и коллизионного регулирования договоров присоединения не являются достаточными для утверждения о том, что Кодекс Бустаманте провозгласил, установил или даже признал приниии автономии воли в международном частном правe.

ОБСУЖДЕНИЕ И ВЫВОДЫ. По итогам проведенного исследования формулируются два основных вывода: во-первых, вопреки распространенной в юридической литературе точке зрения отсутствуют основания для утверждения о том, что Кодекс Бустаманте непосредственно провозгласил принции автономии воли сторон частноправовых отношений международного характера; во-вторых, тезис о закреплении правового принициа международным договором (или иной формой права) требует, по мнению автора, вполне определенной терминологии потожения или совокупности положений соответствующего акта с учетом общей характеристики и особенностей осуществляемого им правового регулирования.

КЛЮЧЕВЫЕ СЛОВА: прИнนиП автономии воли, выбор применимого права, согташение о применимом праве, обязательственный ста- 
тут, Кодекс Бустаманте, унификация коллизионных норм, коллизионное право

ДЛЯ ЦИТИРОВАНИЯ: Новикова Т.В. 2019. О закреплении принципа автономии воли в Кодексе Бустаманте. - Московский журнал международного права. № 3. С. 14-21.

DOI: 10.24833/0869-0049-2019-3-14-21

DOI: 10.24833 / 0869-0049-2019-3-14-21

\section{Tatiana V. NOVIKOVA}

North Caucasian Branch, Russian State University of Justice

187/1, ul. Levanevskogo, Krasnodar, Russian Federation, 350002

tnovikova@inbox.ru

ORCID: 0000-0002-8889-0444

Received 01 May 2019

Approved 05 August 2019

\section{ON THE STIPULATION OF AUTONOMY OF WILL PRINCIPLE BY THE BUSTAMANTE CODE}

INTRODUCTION. Autonomy of will principle (mainly, in case of international contracts) is firmly established in modern private international law. It has become more and more widespread in international treaties unifying choice of law and national legislation of numerous states through the whole XX century. The jurisprudence elaborated a position that the first comprehensive codification of private international law (the Bustamante Code) stipulates autonomy of will principle for parties to international private relations. MATERIALS AND METHODS. The essential technique of this research is bases on the analysis dealing not only with the text of the Bustamante Code, but more with the framework and effects of its elaboration as well as with the peculiarities of its application by member states (especially in the view of general reservations made by several states).

RESEARCH RESULTS. It is pointed out that the Bustamante Code as comprehensive codification of private international law is based on compromise solutions and has been ratified with multiple reservations including those nullifying the very idea of unification. It is proved in series that art. 3 of the Bustamante Code, outlining three categories of legal norms (including voluntary, "applied only by mani- festation, interpretation or presumption of will of the parties or one of the parties"), has too broad character, and fragmentary autonomy of will mentioning in respect of contracts' interpretation and choice-oflaw rules dealing with contracts of adhesion are not sufficient to contend that the Bustamante Code has proclaimed, stipulated or even acknowledged the autonomy of will principle in private international law.

DISCUSSION AND CONCLUSIONS. Two main conclusions are made: firstly, contrary to the point of view widespread in jurisprudence the grounds to contend that the Bustamante Code proclaims autonomy of will principle are absent; secondly, conclusion on legal principle stipulation by the international treaty (or by the other form of law) requires, in author's opinion, quite definite terminology of provision or of the whole text of the corresponding document in the view of concept description and specific peculiarities of its mechanism.

KEYWORDS: autonomy of will principle, choice of applicable law, choice of law agreement, law of a contract, the Bustamante Code, conflict of laws unification, conflict of laws 
FOR CITATION: Novikova T.V. On the Stipulation of Autonomy of Will Principle by the Bustamante Code. - Moscow Journal of International
Law. 2019. No. 3. P. 14-21.

DOI: 10.24833/0869-0049-2019-3-14-21
3 акрепление принципа автономии воли сторон частноправовых отношений с иностранным элементом в международных договорах происходило, в первую очередь, в рамках унификации коллизионных норм. Как указывает Н.Г. Вилкова, первоначально «с унификацией коллизионных норм» были связаны «наибольшие надежды» [Вилкова 1997:132] ${ }^{1}$. При этом удивительный факт истории международного частного права составляет то, что обретшие независимость государства Южной Америки оказались первыми, кто достиг успеха в кодификации его норм [Delić 2019]².

Наиболее известный в этом отношении пример составляет Кодекс международного частного права, именуемый в честь его разработчика - кубинского юриста Антонио Санчеса де Бустаманте-и-Сирвена - Кодексом Бустаманте 3 . Принятие данного Кодекса 20 февраля 1928 г. стало результатом работы Шестой конференции американских государств и оценивается как не- сомненный успех в деле всеобъемлющей кодификации международного частного права ${ }^{4}$.

Впрочем, его применение на практике столкнулось с рядом препятствий. Во-первых, США не стали участниками этого Кодекса, в первую очередь, в силу того, что Конституция США относит такие вопросы к компетенции отдельных штатов [Vickers 1981:627-628]. Во-вторых, большая часть государств-участников ратифицировала Кодекс с разного рода оговорками, из которых критически значимыми являются оговорки общего характера. На основании последних Кодекс не применяется в случае противоречия национальному праву соответствующего государства ${ }^{5}$.

Наконец, региональный характер кодификации и, соответственно, применение Кодекса в рамках узкого круга государств не предполагали его универсальной значимости. Тем не менее последнее обстоятельство на практике дало противоположный результат. С одной стороны,

\footnotetext{
В литературе в качестве преимуществ унификации коллизионных норм указывают ее направленность исключительно на участников частноправовых отношений с иностранным элементом, а также быстроту и простоту самого процесса унификации. В качестве недостатка же упоминается тот факт, что коллизионная норма так или иначе отсылает к национальному праву, которое различается в разных государствах и которое, если оно является иностранным по отношению к lex fori, должно быть установлено судом (см.: Матвеева Т.В. Роль международного договора в международном частном праве: Дис. ... канд. юрид. наук. М. 2006. С. 19-20; Синева Н.А. Унификация правовых норм, регулирующих внешнеторговое обязательство: Дис. ... канд. юрид. наук. Саратов. 2006. С. 153-154).

2 Так, еще в 1877-1878 гг. в г. Лиме состоялся конгресс, результатом которого стало принятие 9 ноября 1878 г. договора, устанавливающего единообразные нормы международного частного права, который, однако, был ратифицирован только Перу и так и не вступил в силу [Rangel 2019:547].

В 1888-1889 гг. в г. Монтевидео состоялся конгресс, результатом которого стало принятие девяти международноправовых инструментов по разным вопросам международного частного права (включая вопросы уголовной юрисдикции). Работа данного конгресса оценивается как успешная, поскольку все государства-подписанты, несмотря на наличие между некоторыми из них политических разногласий, ратифицировали все документы (за исключением Бразилии и Чили, не ратифицировавших три договора из девяти) [Parra-Aranguren 1980:69-70]. Второй конгресс, нацеленный на пересмотр указанных инструментов, состоялся в г. Монтевидео в 1939-1940 гг. [Maekelt 1982:223-224].

3 Кодекс международного частного права (Кодекс Бустаманте 1928 года) (принят в г. Гаване 20.02.1928). - Международное частное право: Сборник документов. М.: БЕК. 1997. С. 3-40. Решение назвать документ Кодексом Бустаманте было принято Шестой международной конференцией американских государств [Tuininga 2009:435].

4 Кодекс Бустаманте включает вступительный раздел (ст. 1-8) и четыре книги: международное гражданское право (ст. 9-231), международное торговое право (ст. 232-295), международное уголовное право (ст. 296-313) и международный процесс (ст. 314-437).

5 Например, Республика Чили ратифицировала Кодекс со следующей оговоркой: «При наличии коллизии между правом Чили и иностранным законом, положения действующих и будущих законов Чили будут превалировать над указанным Кодексом в случае противоречия между ними». Отсюда правоведы сделали однозначный вывод о том, что такие оговорки общего характера приводят к скрытому аннулированию достижений Кодекса [Vickers 1981:628]. Аналогичные оговорки сделали Колумбия, Коста-Рика, Никарагуа и Уругвай [Parra-Aranguren 1980:72].
} 
суды государств - участников Кодекса в отсутствие собственных коллизионных норм по ряду вопросов сформировали тенденцию обращения за решением к Кодексу Бустаманте, в том числе при разрешении коллизий между собственным правом и правом любого другого иностранного государства (не ограничиваясь лишь государствами - участниками Кодекса) [Nadelmann 1971:790] ${ }^{6}$. С другой стороны, Кодекс Бустаманте сам по себе как результат всеобъемлющей кодификации международного частного права привлек внимание мирового сообщества, следствием чего стала диффузия положенных в его основу принципов, включая установленную ст. 3 Кодекса категоризацию национальных законов, в правовые системы многих государств мира [Доронина 2015:131]7.

В отношении закрепления принципа автономии воли в Кодексе Бустаманте нельзя не отметить, что в подавляющем большинстве случаев отечественные правоведы не вполне верно указывают данный Кодекс в числе международных договоров, признающих автономию воли [Занибеков 2016:143; Кондратьева 2003:37; Стригунова 2014:153]. Данный подход получает распространение также в современной учебной литературе 8 . Вместе с тем следует обратить внимание на имеющиеся в зарубежной юридической науке противоположные мнения. В частности, С. Симеонидес указывает, что, хотя автономия воли сторон является древним принципом, она получила нормативное закрепление только в ХХ в. Кодекс Бустаманте и Первый свод конфликтного права США, по мнению автора, отказались от закрепления автономии воли [Symeonides 2014a:1124; Symeonides 2014b:114]. Примечательно и то, что Э. Лоренцен, представивший обзор положений Кодекса, в разделе о договорах не упоминает автономию воли как таковую [Lorenzen 1930:516518].
Основание для вывода о непризнании Кодексом Бустаманте автономии воли сторон частноправовых отношений можно усмотреть в отсутствии в нем предписания, непосредственно провозглашающего данный принцип. Бесспорно, широко известное положение ст. 3 Кодекса Бустаманте устанавливает три категории правовых норм: (1) личных, «следующих за лицами даже при переезде в другую страну»; (2) территориальных, «обязывающих одинаково всех лиц, находящихся на территории» и (3) добровольных, «применяемых только по изъявлению, толкованию или презумпции воли сторон или одной из сторон». По мнению Н.Г. Дорониной, нормы третьей категории «не исходят от органов публичной власти, а устанавливаются самими участниками гражданско-правовых отношений в частноправовых контрактах» [Доронина 2002:73-85]9. Отсюда ученый делает вывод о том, что ст. 3 Кодекса Бустаманте закрепляет наряду с принципом территориальности принцип автономии воли сторон [Доронина 2002:73-85].

Отмечая несомненную важность признания Кодексом Бустаманте значимости воли сторон, мы считаем, что положение ст. 3 указанного документа не может рассматриваться как непосредственно устанавливающее принцип автономии воли по двум причинам. Во-первых, автономия воли в международном частном праве означает вполне определенную возможность сторон избрать материальное право, применимое к конкретному частноправовому отношению (договорному, деликтному и др.), в то время как ст. 3 Кодекса в общей форме допускает возможность существования «добровольных» норм, однако не очерчивает их круг. Во-вторых, классическое прочтение автономии воли позволяет сторонам частноправового отношения достигнуть вполне определенного соглашения о применении материального права, в то время как ст. 3 Кодекса в

\footnotetext{
6 В литературе отмечается, что данная тенденция аналогична тому, как суды в США для разрешения международных коллизий используют правила, разработанные в отношении коллизий права между штатами [Nadelmann 1971:790].

7 Н.Г. Доронина также подчеркивает, что Кодекс Бустаманте оказал «глобальное влияние на развитие международного частного права в каждом государстве международного сообщества» [Доронина 2013:14].

8 Богуславский М.М. Международное частное право: Учебник. М.: Норма; ИНФРА-М. 2019. С 291; Международное частное право: Учебник. Под ред. Г.К. Дмитриевой. М.: Проспект. 2016. С. 304.

9 Отметим, что в случае признания принципа автономии воли сторон частноправовых отношений международного характера речь будет идти не о самостоятельном установлении ими каких-либо норм, а исключительно о возможности выбора норм, по общему правилу исходящих от органов публичной власти какого-либо государства. Даже в случае признания (в первую очередь, международным коммерческим арбитражем) выбора норм lex mercatoria, очевидно, что последние также устанавливаются не исключительно сторонами спорного правоотношения.
} 
общей форме говорит о значимости для применения норм не только изъявления, но также толкования и презумпции воли сторон и даже одной из сторон ${ }^{10}$.

Тем не менее, несмотря на слишком общий, с нашей точки зрения, характер ст. 3 Кодекса Бустаманте, отдельные указания на автономию воли в рамках договорных правоотношений (традиционно первых в развертывании этого принципа) можно усмотреть в ст. 184-185 документа. На основании ст. 184 Кодекса «толкование договоров производится, по общему правилу, в соответствии с законом, который их регулирует». При этом данная статья уточняет, что если «этот закон оспаривается и должен устанавливаться из молчаливо выраженной воли сторон, должно предположительно применяться законодательство, которое предусмотрено» соответствующими коллизионными нормами («личным законом, общим для договаривающихся сторон», а в его отсутствие - «законом места заключения договора»), «хотя в результате к договору может быть применено другое право в соответствии с толкованием воли сторон».

Комментируя положения указанной статьи, следует отметить ряд аспектов. Во-первых, в коллизионном регулировании договорных правоотношений Кодекс Бустаманте, по меньшей мере с точки зрения юридической техники, не придает первостепенного значения автономии воли сторон. Во-вторых, как можно заключить из текста статьи, она оставляет широкое поле для усмотрения правоприменительного органа, который может применить как «право в соответствии с толкованием воли сторон», так и право на основании соответствующих коллизионных норм (в отсутствие критериев выбора между двумя этими возможностями).

Примечательно, что значительно более определенное положение об автономии воли содержится в специальной коллизионной норме, по- священной договорам присоединения. Согласно ст. 185 Кодекса «К договорам о присоединении презюмируется применение закона предлагающей или подготавливающей договор стороны, если отсутствует выраженное или молчаливое согласие». В отличие от нормы, посвященной толкованию всех видов договоров, данная норма является существенно более конкретной, так как устанавливает, что избрание применимого права посредством выраженного или молчаливого согласия превалирует над применяемой в порядке презумпции коллизионной привязкой.

В конечном итоге именно совокупность отрывочных упоминаний об автономии воли лежит в основе имеющейся, в том числе в зарубежной литературе, точки зрения о признании Кодексом Бустаманте возможности сторон договорных правоотношений избрать применимое материальное право [Vickers 1981:627]. При этом М. Альборноз справедливо подчеркивает, что фактически автономия воли в Кодексе имеет подразумеваемый характер [Albornoz 2009:5] ${ }^{11}$. По нашему мнению, подобное «допущение» автономии воли Кодексом Бустаманте свидетельствует исключительно о том, что выбор применимого материального права составляет возможность, которая уже в начале XX в. укоренилась в правосознании юристов многих стран мира как имплицитно присущая сторонам частноправовых отношений международного характера. Однако указанные отрывочные упоминания об автономии воли в аспекте толкования договоров или коллизионного регулирования договоров присоединения никак не означают, что непосредственно Кодекс Бустаманте провозгласил, установил или даже признал принцип автономии воли в международном частном праве.

В дополнение к последнему тезису обратим внимание на то обстоятельство, что Кодекс Бустаманте как первая и до сих пор единственная настолько всеобъемлющая кодификация между-

\footnotetext{
10 Последнее обстоятельство особенно значимо в связи с тем, что даже противники автономии воли как возможности сторон избрать применимое право признают значимость воли одной или обеих сторон для определения обстоятельств, влияющих на локализацию правоотношения (например, на избрание места учреждения юридического лица - в отношении его личного статута, основанного на теории инкорпорации; на избрание места заключения или исполнения договора - в отношении обязательственного статута, основанного на соответствующем критерии, и т.д.). Например, Н.П. Иванов, автор первой в России работы, специально посвященной международному частному праву [Абдуллин 2012:117], выступает против возможности избрания применимого права, но, отстаивая закон места исполнения, заявляет, что автономия контрагентов выражается в том, что они могут выбрать место исполнения своего обязательства [Иванов 2009:90-91].

11 Следует признать, что автор выдвигает точку зрения о возможности сторон договорных правоотношений согласно Кодексу Бустаманте избрать применимое материальное право как превалирующую норму и подчеркивает, что в силу ее подразумеваемого «признания» Кодекс не устанавливает для нее специальных ограничений [Albornoz 2009:5].
} 
народного частного права не мог не быть построен на множестве компромиссных решений ${ }^{12}$. Данный подход обеспечил ему ратификацию со стороны государств-подписантов, хотя и со множеством оговорок, в том числе сводящих на нет саму идею унификации. Как следствие этого, Кодекс априори не мог однозначно провозглашать принцип автономии воли, в особенности с учетом того, что не все государства-участники признавали его на национальном уровне ${ }^{13}$.

По итогам проведенного исследования считаем необходимым сделать два основных вывода. Первый - в отношении принципа авто-

\section{Список литературы}

1. Абдуллин А.И. 2012. О некоторых вопросах зарождения и формирования отечественной науки международного частного права. - Вестник экономики, права и социологии. № 4. С. 117-122.

2. Вилкова Н.Г. 1997. Унификация коллизионных норм в сфере международных коммерческих контрактов. Хозяйство и право. № 11. С. 131-135.

3. Доронина Н.Г. 2002. Унификация права стран Латинской Америки. - Законодательство и экономика. № 10. С. 73-85.

4. Доронина Н.Г. 2013. Унификация права в современных условиях международного сотрудничества. - Проблемы унификации международного частного права. Под ред. А.Л. Маковского, И.О. Хлестовой. М.: Институт законодательства и сравнительного правоведения при Правительстве РФ. С. 13-27.

5. Доронина Н.Г. 2015. Диффузия в праве как направление унификации международного частного права: к вопросу об объекте информационного права. - Журнал российского права. № 5. С. 125-134.

6. Занибеков М.М. 2016. Автономия воли сторон и свобода договора при заключении международного коммерческого договора: действующий правовой механизм или юридическая фикция? - Вестник Московского финансово-юридического университета. № 2. С. $142-153$.

7. Иванов Н.П. 2009. Основания частной международной юрисдикции. - Золотой фонд российской науки международного права. Т. 2. М.: Международные отношения. С. 57-99.

8. Кондратьева Е.М. 2003. Свобода договора и «автономия воли сторон» как гарантии осуществления номии воли - заключается в том, что вопреки распространенной в юридической литературе точке зрения анализ Кодекса Бустаманте не позволяет однозначно утверждать, что он непосредственно устанавливает данный принцип международного частного права. Второй вывод - общего характера - состоит в том, что заключение о провозглашении принципа автономии воли международным договором (а равно - национальным нормативным правовым актом) должно основываться на определенно сформулированных положениях соответствующего документа.

конституционных прав российских участников внешнеэкономической деятельности в международном частном праве. - Вестник Нижегородского университета им. Н.И. Лобаческого. Серия: Право. № 1. C. 33-44.

9. Стригунова Д.П. 2014. Реализация принципа автономии воли сторон в международных коммерческих договорах. - Современное право. № 4. С. 153-158.

10. Albornoz M.M. 2009. Choice of Law in International Contracts in Latin American Legal System. - Centro de Investigación y Docencia Económicas. División de Estudios Jurídicos. No. 36. 40 p. URL: http://repositoriodigital.cide.edu/bitstream/handle/11651/1302/95979. pdf?sequence $=1$ \&isAllowed $=y \quad$ (accessed date: 25.04.2019).

11. Delić A. 2019. The Birth of Modern Private International Law: The Treaties of Montevideo (1889, amended 1940). Oxford Public International Law. URL: https://opil.ouplaw. com/page/Treaties-Montevideo/the-birth-of-modernprivate-international-law-the-treaties-of-montevideo1889-amended-1940 (accessed date: 25.04.2019).

12. Lorenzen E.G. 1930. Pan-American Code of Private International Law. - Tulane Law Review. Vol. IV. No. 4. P. 499528.

13. Maekelt T. de. 1982. Inter-American Codification of Private International Law. - Collected Courses of the Hague Academy of International Law. Vol. 177. P. 221-237.

14. Nadelmann K.H. 1971. The Need for Revision of the Bustamante Code on Private International Law. - American Journal of International Law. Vol. 65. Issue 5. P. 782-793.

15. Parra-Aranguren G. 1980. Recent Developments of Conflict of Laws Conventions in Latin America. - Collected Courses of the Hague Academy of International Law. Vol. 164. P. 55-170.

\footnotetext{
12 В частности, Н.Г. Доронина заявляет, что Кодекс Бустаманте «не содержит законченных норм международного частного права, готовых к применению», а его главная цель «заключалась в защите прав иностранцев, в каком бы из договаривающихся государств они ни находились» [Доронина 2002:73-85].

13 В частности, М. Альборноз указывает, что толкование Кодекса Бустаманте, не признающее автономию воли, соответствовало бы Вводному закону к Гражданскому кодексу Бразилии, в то время как обратное породило бы коллизию в рамках правовой системы Бразилии как государства - участника Кодекса Бустаманте [Albornoz 2009:5].

При этом ст. 9 Вводного закона к Гражданскому кодексу Бразилии (даже в редакции 2018 г.), не упоминая автономию воли сторон, строго предписывает: «Для квалификации и регулирования обязательств применяется закон страны, в которой они возникли» (Вводный закон к Гражданскому кодексу Бразилии. - Научно-учебная группа ВШЭ «Современная конструкция международного частного права». Доступ: https://pravo.hse.ru/data/2019/03/19/1186062916/Bводный\%20закон\%20к\%20ГК\%20Бразилии\%20(ред.2018).pdf (дата обращения: 25.04.2019)).
} 
16. Rangel V.M. 2019. International Law, Regional Developments: Latin America. - International Development Law: The Max Planck Encyclopedia of Public International Law. Ed. by P. Minnerop, R. Wolfrum, F. Lachenmann. Oxford: Oxford University Press. P. 545-559.

17. Symeonides S.C. 2014a. Codifying Choice of Law around the World: An International Comparative Analysis. Oxford: Oxford University Press. $411 \mathrm{p}$.

18. Symeonides S.C. 2014b. Party Autonomy in International Contracts and the Multiple Ways of Slicing the Apple. - Brooklyn Journal of International Law. Vol. 39. Issue 3. P. 1123-1143.

19. Tuininga K. 2009. Cuban Private International Law: Some Observations, Comparisons, and Suppositions. - University of Miami Inter-American Law Review. Vol. 40. Issue 3. P. 433-452.

20. Vickers A.M. 1981. The Choice of Law Clause in Contracts between Parties of Developing and Developed Nations. Georgia Journal of International and Comparative Law. Vol. 11. Issue 3. P. 617-634.

\section{References}

1. Abdullin A.I. O nekotorykh voprosakh zarozhdeniya i formirovaniya otechestvennoi nauki mezhdunarodnogo chastnogo prava [On Several Issues of Origin and Formation of Native Private International Law Science]. - Vestnik ekonomiki, prava i sotsiologii. 2012. No. 4. P. 117-122. (In Russ.)

2. Albornoz M.M. Choice of Law in International Contracts in Latin American Legal System. - Centro de Investigación y Docencia Económicas. División de Estudios Jurídicos. 2009. No. 36.40 p. URL: http://repositorio-digital.cide.edu/bitstream/ handle/11651/1302/95979.pdf?sequence=1\&isAllowed=y (accessed date: 25.04.2019).

3. Delić A. The Birth of Modern Private International Law: The Treaties of Montevideo (1889, amended 1940). Oxford Public International Law. 2019. URL: https://opil. ouplaw. com/page/Treaties-Montevideo/the-birthof-modern-private-international-law-the-treaties-ofmontevideo-1889-amended-1940 (accessed date: 25.04.2019).

4. Doronina N.G. Diffuziya v prave kak napravlenie unifikatsii mezhdunarodnogo chastnogo prava: k voprosu ob ob"ekte informatsionnogo prava [Diffusion in Law as Unification Trend in Private International Law: on the Issue of Information Law Object]. - Zhurnal rossiiskogo prava. 2015. No. 5. P. 125-134. (In Russ.)

5. Doronina N.G. Unifikatsiya prava stran Latinskoi Ameriki [Unification of Law in Latin American Countries]. Zakonodatel'stvo i ekonomika. 2002. No. 10. P. 73-85. (In Russ.)

6. Doronina N.G. Unifikatsiya prava v sovremennykh usloviyakh mezhdunarodnogo sotrudnichestva [Unification of Law in the Modern Framework of International Cooperation]. - Problemy unifikatsii mezhdunarodnogo chastnogo prava. Pod red. A.L. Makovskogo, I.O. Khlestovoy [Problems of Unification in Private International Law. Ed. by A.L. Makovskii, I.O. Khlestova]. Moscow: Institut zakonodatel'stva i sravnitel'nogo pravovedeniya pri Pravitel'stve RF Publ. 2013. P. 13-27. (In Russ.)

7. Ivanov N.P. Osnovaniya chastnoi mezhdunarodnoi yurisdiktsii [Grounds for Private International Jurisdiction]. -
Zolotoi fond rossiiskoi nauki mezhdunarodnogo prava. T. 2 [Golden Fund of Russian International Law Science. Vol. 2]. Moscow: Mezhdunarodnye otnosheniya Publ. 2009. P. 57-99. (In Russ.)

8. Kondrat'eva E.M. Svoboda dogovora i "avtonomiya voli storon" kak garantii osushchestvleniya konstitutsionnykh prav rossiiskikh uchastnikov vneshneekonomicheskoi deyatel'nosti $v$ mezhdunarodnom chastnom prave [Freedom of Contract and 'Parties' Autonomy of Will" as Guarantees for Execution of Constitutional Rights of Russian External Economic Activity Participants in Private International Law]. - Vestnik Nizhegorodskogo universiteta im. N. I. Lobacheskogo. Seriya: Pravo. 2003. No. 1. P. 33-44. (In Russ.)

9. Lorenzen E.G. Pan-American Code of Private International Law. - Tulane Law Review. 1930. Vol. IV. No. 4. P. 499-528.

10. Maekelt T. de. Inter-American Codification of Private International Law. - Collected Courses of the Hague Academy of International Law. Vol. 177. 1982. P. 221-237.

11. Nadelmann K.H. The Need for Revision of the Bustamante Code on Private International Law. - American Journal of International Law. 1971. Vol. 65. Issue 5. P. 782-793.

12. Parra-Aranguren G. Recent Developments of Conflict of Laws Conventions in Latin America. - Collected Courses of the Hague Academy of International Law. 1980. Vol. 164. P. 55-170.

13. Rangel V.M. International Law, Regional Developments: Latin America. - International Development Law: The Max Planck Encyclopedia of Public International Law. Ed. by P. Minnerop, R. Wolfrum, F. Lachenmann. Oxford: Oxford University Press. 2019. P. 545-559.

14. Strigunova D.P. Realizatsiya printsipa avtonomii voli storon v mezhdunarodnykh kommercheskikh dogovorakh [Realization of Parties' Autonomy of Will Principle in International Commercial Contracts]. - Sovremennoe parvo. 2014. No. 4. P. 153-158. (In Russ.)

15. Symeonides S.C. Codifying Choice of Law around the World: An International Comparative Analysis. Oxford: Oxford University Press. 2014a . 411 p.

16. Symeonides S.C. Party Autonomy in International Contracts and the Multiple Ways of Slicing the Apple. - Brooklyn Journal of International Law. 2014b. Vol. 39. Issue 3. P. 1123-1143.

17. Tuininga K. Cuban Private International Law: Some Observations, Comparisons, and Suppositions. - University of Miami Inter-American Law Review. 2009. Vol. 40. Issue 3. P. 433-452.

18. Vickers A.M. The Choice of Law Clause in Contracts between Parties of Developing and Developed Nations. - Georgia Journal of International and Comparative Law. 1981. Vol. 11. Issue 3. P. 617-634.

19. Vilkova N.G. Unifikatsiya kollizionnykh norm v sfere mezhdunarodnykh kommercheskikh kontraktov [Conflict of Laws Unification in the field of International Commercial Contracts]. - Khozyaistvo i pravo. 1997. No. 11. P. 131-135. (In Russ.)

20. Zanibekov M.M. Avtonomiya voli storon i svoboda dogovora pri zaklyuchenii mezhdunarodnogo kommercheskogo dogovora: deistvuyushchii pravovoi mekhanizm ili yuridicheskaya fiktsiya? [Parties' Autonomy of Will and Freedom of Contract in Conclusion of International Commercial Contract: Valid Legal Mechanism or Legal Fiction?]. - Vestnik Moskovskogo finansovo-yuridicheskogo universiteta. 2016. No. 2. P. 142-153. (In Russ.) 


\section{Информация об авторе}

Татьяна Васильевна Новикова,

кандидат юридических наук, доцент, заведующая кафедрой международного права, Северо-Кавказский филиал, Российский государственный университет правосудия

350002, Российская Федерация, Краснодар, ул. им. Леваневского, д. 187/1

tnovikova@inbox.ru

ORCID: 0000-0002-8889-0444
About the Author

Tatiana V. Novikova,

Cand. Sci. (Law), Associate Professor, Head of the International Law Department, North Caucasian Branch, Russian State University of Justice

187/1, ul. Levanevskogo, Krasnodar, Russian Federation, 350002

tnovikova@inbox.ru

ORCID: 0000-0002-8889-0444 